\title{
壁近傍乱流における壁近傍層の乱流特性*
}

$\begin{array}{llll}\text { 三宅 } & \text { 裕 } \\ \text { 範 } & \text { 过和 }{ }^{* 2} \text {, 鈴 木 公 } \text { 雄 }^{* 1} \text { 介 }^{* 2}\end{array}$

\section{Turbulence Property in the Near-Wall Layer}

\author{
Yutaka MIYAKE*3, Koichi TSUJIMOTO, \\ Norikazu SATO and Yusuke SUZUKI \\ ${ }^{* 3}$ Department of Mechano-physics, Graduate School of Osaka University, \\ 2-1, Yamada-oka, Suita, Osaka, 565-0871 Japan
}

\begin{abstract}
Model simulations to show autonomous property of near-wall layer below lower edge of logarithmic layer are conducted for a channel flow. A model to remove interaction between two layers top and below of a plane parallel to the wall, by assuming zero wall-normal velocity on it is employed for this purpose. It turned out that near-wall layer needs a definite minimum thickness to maintain turbulent regime if no interaction with upper layer is allowed and that the layer has universal turbulent structure if turbulent regime is allowed irrespective of any interaction with above layer. The universality holds for any wall condition such as to lower wall friction, with different structure depending on each wall condition. Simulations to trace time evolution of a small pair of quasistreamwise vortices submerged in a laminar flow of mean turbulent velocity distribution were also conducted to see the basic structure of the universal near-wall turbulence. The energy budged of the grown-up structure which is composed of a couple of hairpin vortices and subsidiarily generated quasi-streamwise vortices is similar to that observed in natural turbulent channel flow.
\end{abstract}

Key Words: DNS, Near-wall Turbulence, Autonomous Property, Hairpin Vortex

\section{1. ま え がき}

溝乱流は流れを維持するためのエネルギを外部から受 け取り，その多くを平均流のひずみ速度による粘性消 散によって失い，他は乱れエネルギに供給する。乱れ は受け取ったエネルギを乱れの渦が作るひずみ速度に よる粘性消散によって消費し, 全体のエネルギの平衡 が保たれる．壁乱流では壁近傍領域が乱れの活動のほ とんどを占め, 遠方領域の乱れは主として壁近傍領域 から拡散によって供給されると理解されている。すな わち, 乱流ではさまざまなスケールの渦が運動量の交 換を行うのでより離れた層の間での干渉が生じ, 層全 体の乱れの維持に寄与していると考えられる。したが ってこの連鎖を制御して乱れに落ちるエネルギ，すな わち乱れエネルギ生成を抑制すれば乱れは弱くなり， 壁面抗力の低減などが実現される.

しかし，滑面壁の場合，壁近傍領域は摩擦速度 $u_{\tau}$ と動粘性係数レで決まる壁指標に対して相似性があ り，遠方領域は流路幅を代表長さとする相似性があ

* 原稿受付 2000 年 2 月 18 日.

*1 正員, 大阪大学大学院工学研究科 (画 565-0871 吹田市山田 丘 2-1).

*2 大阪大学大学院

E-mail : miyake@mech.eng.osaka-u.ac.jp
る、著者らは先に粗面乱流の数值シミュレーションを 行い(1), 粗さ要素高さの数倍以上の対数域より上方の 壁遠方領域の乱れは壁の性状に無関係に，壁面抗力の 大きさのみによって決まる相似性を確認した.このこ とは瞬時の構造はともかく，少なくとも統計平均では 壁遠方領域と壁近傍領域とは独立な乱れの機構をもつ ことを示唆している. 最近 Jiménezら (2) はミニマル 溝(Minimal Channel)乱流を用いて壁近傍層の自律 性を確認し，その自律性の心要十分条件がストリーク であることを指摘している。ここに自律性とは壁近傍 層がその上方の層の乱れなしに乱流を維持すること でこの結果はこれまで支持されてきた層間の干渉を 必須とする考え方を覆すものである．壁乱流の制御の ためにリブレットなど，壁面近傍を操作するさまざま な方法が試みられているが，この自律性に対する壁面 性状の影響は制御機構の理解のうえで関心がもたれ る.

本報告ではミニマル溝でなく周期性の影響の小さい 計算領域で, 独自の構造と乱れ生成の機構が存在する 対数域以上の層と壁近傍層との干渉の数值実験を行 い, 単一渦の成長のシミュレーションと合せて壁近傍 層の自律性とその自律的な乱れの特性を検討する。 
Table 1 Calculation condition of data bases

\begin{tabular}{|l|c|c|c|}
\hline No. & Volume $\left(L_{x}, L_{y}, L_{z}\right)$ & $\operatorname{Grid}\left(N_{x}, N_{y}, N_{z}\right)$ & $R e_{\tau}$ \\
\hline 1 & $4 \pi H \times 2 H \times \pi H$ & $128 \times 129 \times 64$ & 150 \\
2 & $2 \pi H \times 2 H \times \pi H$ & $128 \times 257 \times 256$ & 395 \\
\hline
\end{tabular}

\section{2. 計 算 方 法}

幅 $2 H$, 流れ方向長さ $L_{x}$, 流れに直交方向の長さ $L_{z}$ の直方体計算領域を考元る。平均流の向きに $x$, 壁垂直方向に $y$ ，スパン方向に $z$ をとり，それぞれの 向きの速度成分を $u, v, w$ とし, 時間平均量にバー $\left(^{-}\right)$を付し, 変動成分にプライム $\left(^{\prime}\right)$ を付して表す。 速度, 圧力は平均壁面摩擦速度 $\bar{u}_{\tau}$ と密度 $\rho$ を用いて 無次元化する．また $\bar{u}_{\tau}$ ならびに動粘性係数 レで無次 元化した物理量に(+)を付す。

$x, z$ 方向には周期条件を課し, 空間の離散化はスペ クトル法により行った。計算コードの詳細は文献 (3) による，摩擦抗力を低減する場合の計算も含むが, 流 量を一定に保つのでなく，圧力こう配をつねに一定に 保った。本計算では 2 種類のレイノルズ数について検 討する，それぞれの計算領域，格子数ならびに $\bar{u}_{\tau}$ と $H$ を用いたレイノルズ数 $\left(R e_{\tau}=\bar{u}_{\tau} H / \nu\right)$ を表 1 に示 す.

以下では壁から一定距離の壁に平行な面内におる て，そこでの内外層間の干渉を遮断するため，その位 置での壁垂直方向速度のみを零とする，このような流 路内部での境界条件の設定のために, Goldstein ら ${ }^{(4)}$ の方法を採用した。これは流路内の指定する場所での 速度条件を满足するように局所的な外力をフィードバ ックさせる方法で次式に示す外力を運動方程式に加え る.

$$
f_{i}\left(\boldsymbol{x}_{s}, t\right)=\alpha \int_{0}^{t} u_{i}\left(\boldsymbol{x}_{s}, \tau\right) d \tau+\beta u_{i}\left(\boldsymbol{x}_{s}, t\right)
$$

ここで $x_{s}$ 㞲指定した位置を， $\alpha, \beta$ は指定した位置 での粘着条件を満足するように負の定数值を与える. 計算の詳細は文献 $(4)$ に記載されているので省略する が $\alpha, \beta$ は経験的に決められ, 本計算では壁垂直速度 $v$ を零とするように $\alpha=-4 \times 10^{5}, \beta=-2 \times 10^{2}$ が選ば れた。計算では両壁面側で干涉遮断層を設ける。した がって溝の中央面を境に, 流れは平均的に対称とな る.

\section{3. 壁垂直速度を制御した壁乱流}

$3 \cdot 1$ 平滑面溝乱流壁近傍の縦渦を抑制すると 壁面摩擦が低下する。縱渦抑制の方法はさまざまに可

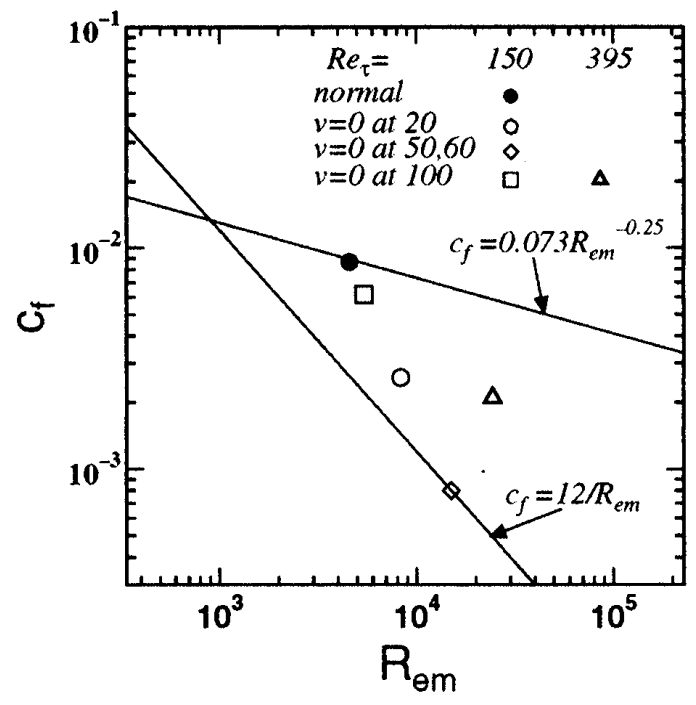

Fig. 1 Fricition coefficient for the case of a channel flow having a manipulating layer

能で, 例えば壁近傍の層で非等方粘性を仮定すると摩 擦抗力が低減できる(5).

一方，壁乱流では乱流拡散によって壁遠方から流れ の運動エネルギが運ばれるので垂直速度 $v$ を抑制す ることによって層間のエネルギ交換を阻止すれば乱れ を制御でき，壁近傍の維渦を抑制できると期待され る. LEBU は実用性は小さいが，このことを目的とし ている、そこで本報では壁からある高さの壁に平行な 面内で壁垂直速度 $v$ を強制的に零にする方法による 乱流制御の数值実験を行う。上述の Jiménez ら ${ }^{(2)} の$ 数值実験では，壁からある高さ以上の乱れをすべて人 工的に消して，上方の層の乱れの影響を零にする方法 をとっている．本報は層間の干渉効果を調べるため の，干渉を遮断する数值実験である，以下，この制御 を干渉遮断制御と呼ぶことにする。

図 1 は壁面摩擦抵抗係数 $c_{f}=2 \bar{u}_{\tau}^{2} / \bar{u}_{m}^{2}\left(\bar{u}_{m}\right.$ : 溝間平 均流速)のレイノルズ数 $\operatorname{Re}_{m}\left(=2 \bar{u}_{m} H / \nu\right)$ に対する変 化である. $c_{f}=0.073 R e_{m}^{-0.25}$ の直線は平滑面の溝乱流 の場合， $c_{f}=12 / R e_{m}$ のそれは層流の場合である。 $\diamond$, 口印は $R e_{\tau}=150$ で $y_{h}^{+}=20,50,100\left(y_{h}\right.$; 干渉遮断 位置)で, $v=0$ と扔いた場合で，・印はこの操作をし

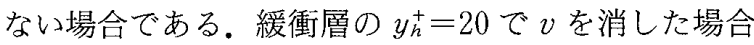
は摩擦係数 $c_{f}$ は乱流と層流の中間にあり, 低減率 $R_{t}\left[=\left(c_{f n}-c_{f}\right) / c_{f n} \times 100(\%), c_{f n} ;\right.$ 遮断制御された場 合の $R e_{m}$ に相当する平滑面溝乱流の壁面摩擦抵抗係 数] は $66 \%$ となる。 $y_{h}^{+}=50$ の場合， $c_{f}$ は層流の值に なり，流れが完全に層流化することがわかる，完全な 層流化は $y_{h}^{+}=60$ でも同様に生じる，制御の面をさら に高くして $y_{h}^{+}=100$ とすると $c_{f}$ は再び増加し, 摩擦 

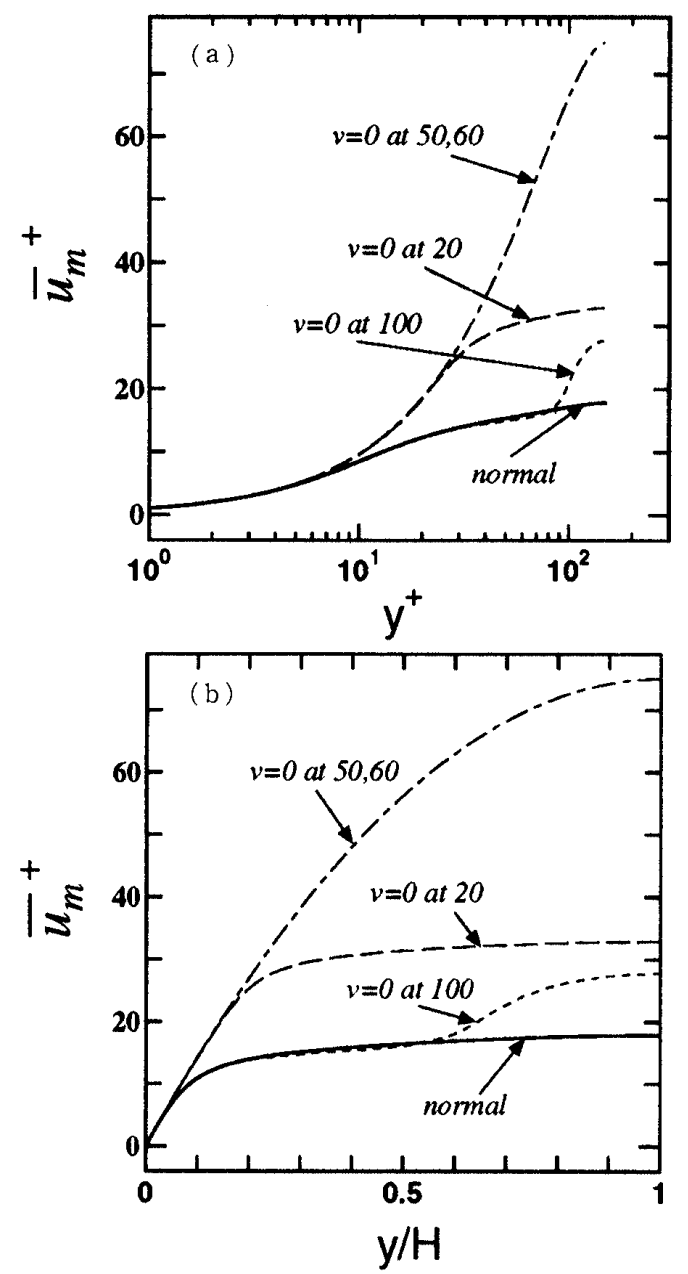

Fig. 2 Velocity distribution across a chanel in (a) wall coordinate and (b) global coordinate

抗力の低減率は小さくなる $\left(R_{t}=28 \%\right)$.

$R e_{\tau}=395$ の場合も同様で制御面を $y_{h}^{+}=100$ とする と $c_{f}$ の值は層流と乱流の中間 $(\triangle)$ になり, 完全な層 流にはならない。

このときの流れの状態を調べるために断面内平均速 度分布 $\bar{u}_{m}$ を調べると図 2 のようになる。図2(a)， (b)はそれぞれ横軸を $y^{+}=y \bar{u}_{\tau} / \nu, y / H$ として $\bar{u}_{m}^{+}=$ $\bar{u}_{m} / \bar{u}_{\tau}$ の分布を表している. 図 2 中一点鎖線は層流の 場合の速度分布で， $y_{h}^{+}=50,60$ で遮断制御した場合と 一致する. $R e_{\tau}=150$ の $y_{h}^{+}=20$ で干涉遮断制御した 場合， $y^{+} \leq 20$ の層は完全に層流化され，その層までは 速度分布は層流のそれになる。しかし，その上方に緩 衝層が現れ，再び発達した乱流になる。制御面をy古 $=50,60$ にするとほほ全領域が完全に層流の速度分布 になる。また， $y_{h}^{+}=100$ のときは制御面近傍を除いて 壁面側は発達した乱流を維持するが，その上方は層流 になる。このことは乱流せん断応力がほぼ零となるこ とからも確かめられる(図省略)，Re $e_{\tau}=395$ で制御面 を $y_{h}^{+}=100$ とした場合, 後述の図 4 に示すように,
$R e_{\tau}=150$ で $y_{h}^{+}=100$ の場合と同様, 制御面の壁側は 乱流が維持される。

干涉を遮断した場合に壁側が乱流を維持するなら ば，その速度分布は遮断制御がない場合と同じであ る，以上の結果から，遮断面以下の壁近傍層は遮断面 の高さがある高さ以下では乱流を維持できず, 逆に遮 断面以下の層が乱流を維持する場合, その層内の流れ の速度分布は普遍的である。

壁近傍層の平均流はその上方の流れから乱流せん断 応力の拡散効果によりエネルギを受け取り，その一 部を乱れの生成に消費する. 制御面が $y^{+}=50 \sim 60$ 以 下のときその内側で乱れが完全に消えるのは, 壁側の 平均流が乱れ生成のために消費するエネルギの不足に よるためである。壁にごく近い層が乱れを維持するた めには, $y^{+}=50 \sim 60$ 以上の厚さがあればよい。 Jiménez ら (2) らはミニマル寸法に近い溝乱流におい て, 人工的に壁面からある高さ以上の乱れを消去した 場合の数值実験を行い, 壁面から $y^{+}=50 \sim 60$ までの 層はその上方の乱れには無関係な自律性があることを 示した。 上述の結果はこの結果を確認するものであ る.しかし, Jiménez らは自律的な壁近傍層の乱れの 特性が制御のない場合とは詳細には一致しない結果を 示している.

次に遮断制御した場合の壁近傍層の乱れの特性を述 べる. 図 3 は $R e_{\tau}=150$ で, 制御面が $y_{h}^{+}=100$ の場合 の (a) 乱れ強さ分布, ( b ) 渦度分布, (c) 平均流の工 ネルギの釣合い分布，(d)乱れエネルギの釣合い分布 である、いずれも実線は通常の溝乱流の場合, 記号は 制御した溝乱流の場合である. 平均流のエネルギは圧 カこう配がなす仕事の項 (・), 乱流渦による仕事の項 $(\triangle)$, 粘性消散項 $(\diamond)$, 粘性拡散項 $(\square)$, 乱流拡散項 (ム)からなる．また乱れエネルギの釣合いは $k$ の輸 送方程式の $D k / D t$ の右辺で, 生成項(•), 消散項 $(\diamond)$, 乱流拡散項 $(\boldsymbol{\Delta})$, 粘性拡散項 $(口)$, 圧力拡散項 $(\triangle)$ からなる. $y^{+}=100$ の面で壁垂直速度が零となる ために壁垂直方向変動速度 $v^{\prime} か ゙ ~ y^{+}=60 \sim 100$ で弱く なり, 乱流せん断応力が低下して遮断位置近傍は層流

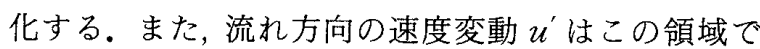
乱れ渦が弱くなって乱流混合が弱まり，乱れの再配分 が抑制されるためストリークが強くなる。このシミュ レーションでは流れ方向速度には制御を行っていない

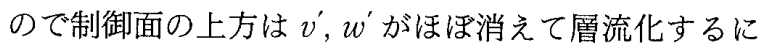
もかかわらず，ストリークが残りびが消えない。し かし, $y^{+} \sim 60$ 以下では制御のない溝乱流の場合とほ ぼ一致する。渦度強度についても同様の挙動を示す。 すなわち $y^{+} \sim 60$ 以下では流れはその上方の乱れとの 

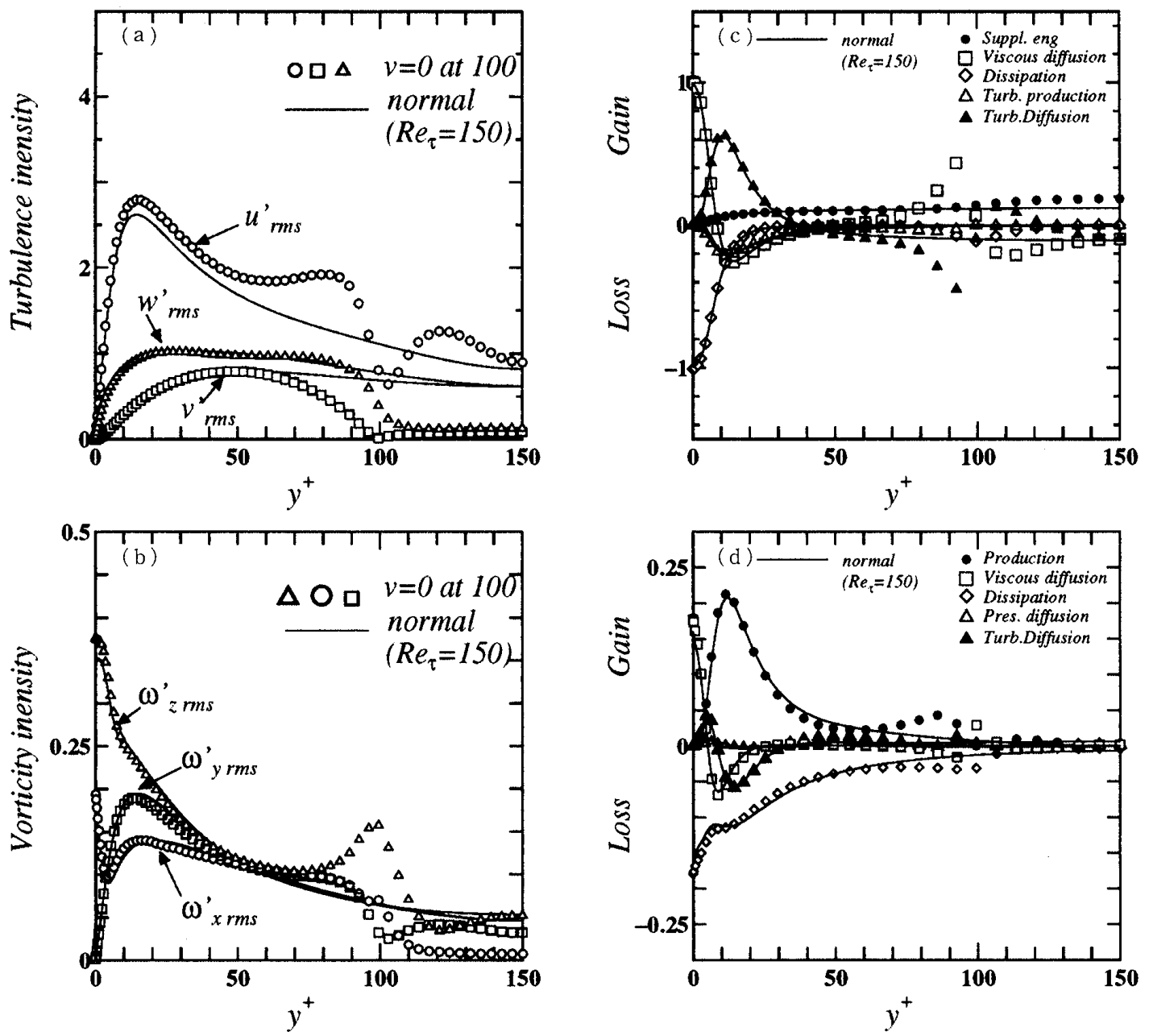

Fig. 3 Mean turbulence properties in a channel having the manipulating layer in the case of $y_{h}^{+}=100$ at $R e_{\tau}=150$, (a) turbulent intensity, ( b ) vorticity intensity, (c) mean energy budget and (d) turbulent energy budget

干涉を遮断しても，その平均ならびに乱れエネルギの 壁垂直方向の釣合い分布は通常乱流と変わらない. 平 均流のエネルギ釣合いに変化がないことは, 平均流速 分布が変わらないことと併せて, $y^{+} \sim 60$ 以下の壁近 傍層の乱れは生成, 消散を含めた細かい構造に至るま で，その領域の乱れを維持する普遍性のある自律構造 が存在することを示している.

図 4 は $R e_{\tau}=395$ の場合の乱れエネルギの釣合い分 布である，壁近く $y^{+} \sim 60$ 以下について，上述の結論 はレイノルズ数の変化によらず成立する。制御面上方 では乱流が回復し, 制御面近傍では壁近傍に近い分布 が生じる.

図1に示したように壁垂直方向速度の制御による $c_{f}$ の低下には制御面の位置とレイノルズ数によって その割合に違いが現れる。岶 は図 $2(\mathrm{~b})$ の速度分布 の積分值になるから， $c_{f}$ は図 $2(\mathrm{~b})$ のそれぞれの場合 の線の下方の面積の二乗に逆比例する．したがって乱 流域が形成されるとその速度分布は平たんになり $c_{f}$
が大きくなる。

一般にリブレットなど壁面上での制御のみの場合の 抵抗削減率は高分子の卜ムス効果の場合に比べて非常 に小さい．抵抗削減率を上げるには壁遠方をできるだ け層流化することが必要で，卜ムス効果はこれを実現 している.

$R e_{\tau}=150$ の場合についてみると, $y_{h}^{+}=20$ の場合は $y^{+} \sim 50$ 以上で乱流が維持され，速度分布が平たんに はなるが抵抗削減率は $50 \%$ を超える。壁近傍では速 度こう配が大きく層流化する層の厚さが小さくともそ の上方に生じる等価的な滑り層が $\bar{u}_{m}$ を增大させるの で $c_{f}$ への低下の寄与は大きい。また, $y_{h}^{+}=100$ の場 合は, 制御面の上方が層流化するが壁面側が乱流を維 持するので $\bar{u}_{m}$ が小さく $c_{f}$ の低下も少ない.

$R e_{r}=395$ で $y_{h}^{+}=100$ の場合は制御面の上方は完全 には層流にはならず流路中央部付近では乱流が維持さ れる。

この数值実験の場合, レイノルズ数は十分大きくな 


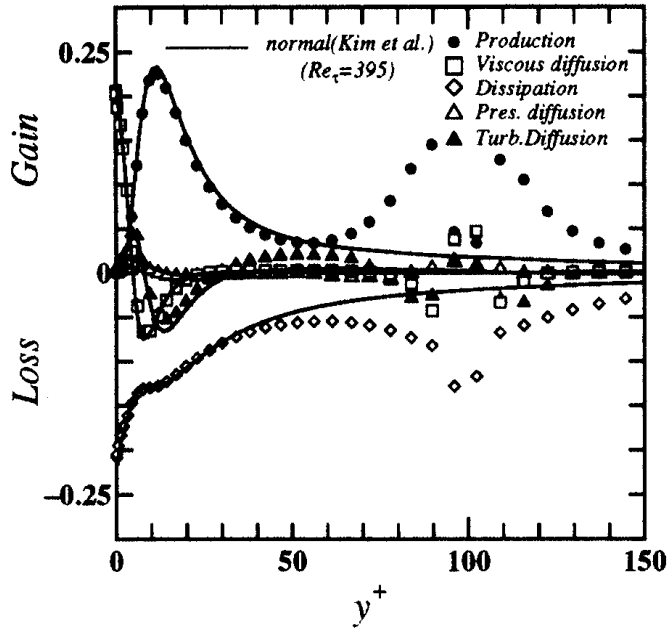

Fig. 4 Budget of kinetic energy of fluctuating velocity for the case of $y_{h}^{+}=100$ at $R e_{\tau}=395$

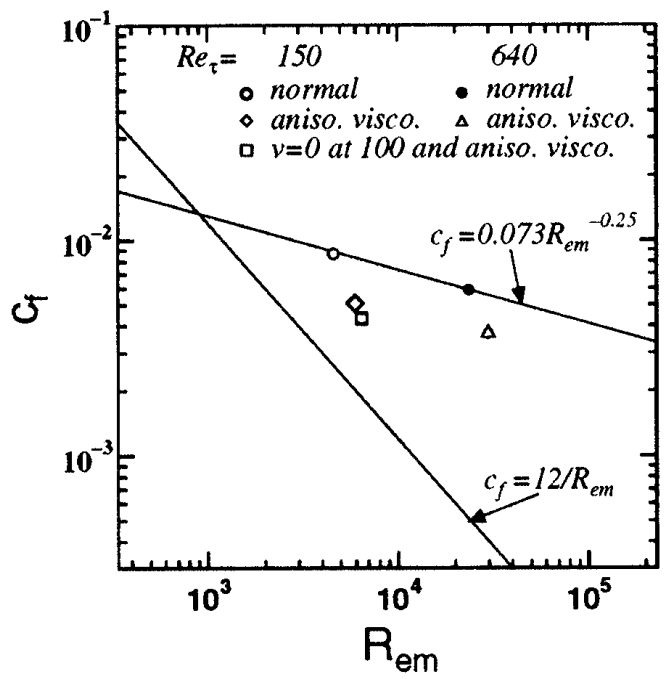

Fig. 5 Fricition coefficient for the case of channel flow having a manipulating layer and manipulating wall

いので, 制御面の上方が層流になるか乱流を維持する かは制御面上方の流路中央部の幅が乱れの渦を許容し うるに十分広く，かつその部分のレイノルズ数が流れ の層流不安定を誘起するか否かによっている。制御面 が $y_{h}^{+}=100$ のとき $c_{f}$ の削減率は $R e_{\tau}=395$ の場合 $\left(R_{t}=64 \%\right)$ のほうが $R e_{\tau}=150$ の場合 $\left(R_{t}=28 \%\right)$ 上 り大きくなる．前者では制御面上方で乱流が維持され るものの, 制御面近傍で部分的に層流化し，流れの滑 りが生じてその上方の流速が増大するからである。

$3 \cdot 2$ 壁面制御した場合の溝乱流乱れの壁近傍 構造の普遍性は壁の条件に依存すると考えられる。壁 面で摩擦抗力が低減された場合, 壁近傍層での乱机 ネルギも低下するので乱れエネルギの釣合い分布にも 変化が現れると考えられる. $3 \cdot 1$ 節の結果が壁面の条

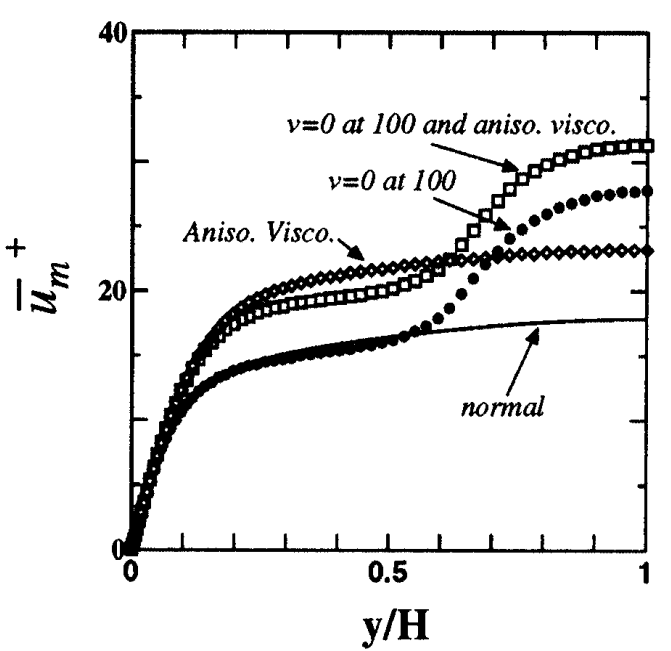

Fig. 6 Velocity distribution for the case of the channel having the manipulating wall and manipulating layer at $R e_{\tau}=150$

件によってどのように変化するかを調べるために壁面 摩擦抗力を低隇させた場合について $3 \cdot 1$ 節と同様の数 值実験を行った。壁面摩擦抗力の低減には縦渦を抑制 すればよく，そのためにいくつかの方法があるが、こ こでは壁面近傍でスパン方向にのみ動粘性係数が他の 方向より大きくなるような非等方粘性を仮定した。こ の仮定は等価的にストリークの速度こう配 $\partial u^{\prime} / \partial z$ 緩和することになる。

以下に示す計算結果は, $R e_{\tau}=150$ で, 非等方粘性 による付加的応力項として運動方程式の粘性項に $\alpha_{n} \partial^{2} v / \partial z^{2}$ を加之， $\alpha_{n}=5$ と招き, $y^{+}=0 \sim 35$ の幅の圈 にこの付加応力を適用した場合である．ただし，vは 流速ベクトルである．図 5 は摩擦抗力低減を行った場 合の摩擦抗力係数 $c_{f}$ で, 図 1 と同じ量である。 ○印

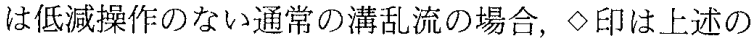
非等方粘性を仮定した遮断制御のない場合 $\left(R_{t}=\right.$ $39 \%)$ ， 口印はさらに $y^{+}=100$ の面で $v=0$ の制御を 加えた場合 $\left(R_{t}=47 \%\right)$ である。また，参考のため $R e_{\tau}=640$ の通常溝乱流 $(\bullet)$, これに $y^{+}=0 \sim 35$ の幅 の非等方粘性を加えるが遮断制御のない場合 $(\triangle)$, $\left(R_{t}=44 \%\right)$ も併せて示した。レイノルズ数が変化し ても非等方粘性による壁近傍の抑制の効果は同程度に 有意な抵抗削減効果が現れる。

遮断制御した場合, 遮断面の高さと壁近傍が層流化 する特性の関係は $3 \cdot 1$ 節までの場合と同じで,ここに 示す $y_{h}^{+}=100$ の場合も遮断面以下は乱流が維持され る.

図 6 は断面内流速分布で実線は通常の溝乱流，・印 は $y^{+}=100$ で干渉遮断制御のみを行った場合, ロ, 


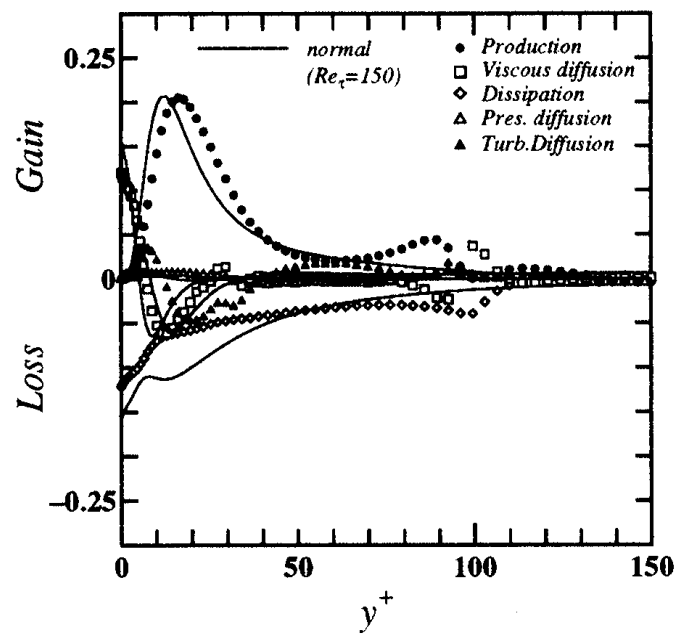

Fig. 7 Budget of kinetic energy of fluctuating velocity for the case of $y_{h}^{+}=100$ at $R e_{\tau}=150$

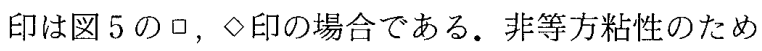
に緩衝層の厚さが増し，また， $y^{+}>100$ に干渉遮断制 御による層流化を示す増速域が現れる。

図 7 は乱れエネルギの釣合い分布で線は制御をまっ たく行わない $R e_{\tau}=150$ の通常溝乱流の場合, 記号は 非等方粘性制御に $y_{h}^{+}=100$ で干渉遮断制御を加えた 場合である.壁近くの $y^{+} \leq 35$ では粘性の非等方部分 が消散率 $(\diamond)$, 粘性拡散率(口)に付加的な成分を生成 するが図には含めていない. $y^{+} \leq 35$ の乱れ抑制層の ために記号で表される分布は線に比べてそれぞれ右に 移動する。しかし，乱れエネルギの生成率(・)にみら れるように, 最も生成率が強い緩衝層は壁からの距離 を移すだけでほぼ同じ強さ，同じ幅で存在する。つま り，壁近傍の薄い層の乱れを抑制すれば図 6 のように 「滑り」が大きくなって流量が増すがその滑り層の外 側に改めて緩衝層が生成される。一般にマイクロジェ ットなど, 壁面を操作して壁面摩擦抗力を低減する場 合は操作の影響が到達する距離は壁から壁指標にして 数十程度までであるから, 乱れの構造の変化も図 7 に 示寸程度と考えられる。図 7 には示していないが非等 方粘性による制御のみの場合の壁近傍での様子は干涉 制御も同時に行った場合とほぼ変わらず，通常の溝乱 流の場合と同様，壁近傍層の乱れの自律性は壁面条件 にはよらず成り立っている。

\section{4. 渦の成長のシミュレーション}

$4 \cdot 1$ 注入するじょう乱 以上のように $y^{+}=50$ 〜60 以下の壁近傍層の乱れ構造は普遍的であること がわかった．本節ではその普遍構造の基本的な性質を 調べるために単一の渦の成長をシミュレートする。こ
のために平均速度分布は乱流のそれであるが乱れはな い層流を考えこれに渦の種を注入する，注入する渦の 種は層流中にじょう乱を加えることになるが，加える じょう乱は任意ではなく，与えたじょう乱は生成する 乱れエネルギが粘性による消散量以上であるような条 件を満たすものでなければならない.このために Zhouら ${ }^{(6)}$ のシミュレーシンの方法を適用する.こ の方法は, DNSによって得られた溝乱流の流れ場か ら線形統計評価法(LSE) (7) を用いて渦を抽出する。 点 $x$ でのイベントを代表する変動速度が $V=V_{j}$ であ るとき, その近傍の点 $x+r$ の速度 $\boldsymbol{u}(x+\boldsymbol{r})$ は近似 的に

$$
u_{i}=u_{i}(\boldsymbol{x}+\boldsymbol{r}) \simeq L_{i j}(\boldsymbol{x} ; \boldsymbol{r}) V_{j}(\boldsymbol{x})
$$

と表すことができるものとし, 最小二乗法によって誤 差を最小にするなら $L_{i j}$ は次式を解いて得られる。

$$
R_{j l}(\boldsymbol{x}) L_{i j}(\boldsymbol{x} ; \boldsymbol{r})=Q_{l i}(\boldsymbol{x} ; \boldsymbol{r})
$$

ただし, $R_{i j}(\boldsymbol{x})=\left\langle u_{i}(\boldsymbol{x}) u_{j}(\boldsymbol{x})\right\rangle, Q_{i j}(\boldsymbol{x} ; \boldsymbol{r})=$ $\left\langle u_{i}(x) u_{j}(\boldsymbol{x}+\boldsymbol{r})\right\rangle$ はそれぞれ変動速度 $u_{i}$ の自己相関 と二点相関で,〈・統計平均である.

種として注入する洞は縦渦対で, 流れ場の重要なイ ベントに対応し，それを代表する速度ベクトル $V=$ $V_{j}$ を指定して得られる。壁近傍乱流を特徵づけるイ ベントは吹上げとそれによって生成される低速ストリ ークであるからZhou ら (6) と同様, 吹上げの最も高い 頻度の速度べクトルを指定する。

本研究では $R e_{\tau}=150$ の溝乱流の $y^{+}=50$ の面内で の変動速度 $u^{\prime}-v^{\prime}$ 平面の $-\int u^{\prime} v^{\prime} d u^{\prime} d v^{\prime}$ の等値線から, その最大值を与える変動速度べクトル $u^{\prime}=-1.83, v^{\prime}$ $=1.02$ をイベントとして選んだ。ただし，Zhou ら ${ }^{(8)}$ が述べているように埋め込んだ種のその後の成長は $\boldsymbol{V}=V_{j}$ の強さによって大きく変わる.ここでは上記 の $V$ を3倍の強さにした速度べクトルを与えて式 （2）方ら周囲の速度場を含む縦渦対を得た。

$4 \cdot 2$ 渦の発達図 8 は上述のように与えた渦の 種のその後の時間的発展を示す. 図 $8(\mathrm{a}) \sim(\mathrm{d})$ は順 に初期渦埋込み後, $T^{+}=24,96,168,240$ の時刻におけ る渦構造で渦は $Q^{+}=0.01 の$ 等值面で表してある.な お，Zhou ら ${ }^{(8)}$ は $Q$ でなく速度こう配テンソルの固有 值の虚部の大きさを渦の表示に用いているが抽出され る渦形状はほぼ同じになる。 $T^{+}=24$ でレッグが伸び, 続いて二つのレッグがアーチ状のへッドでつながり， $T^{+}=96$ ではへッドが大きく成長してへアピン瀜の形 になる、同時に下流側に縦渦が生成し，上流側には第 2 のヘアピンのヘッドが現れる． $T^{+}=168$ ではこの二 次へアピン渦のヘッドがより成長し二次的な縌渦が数 


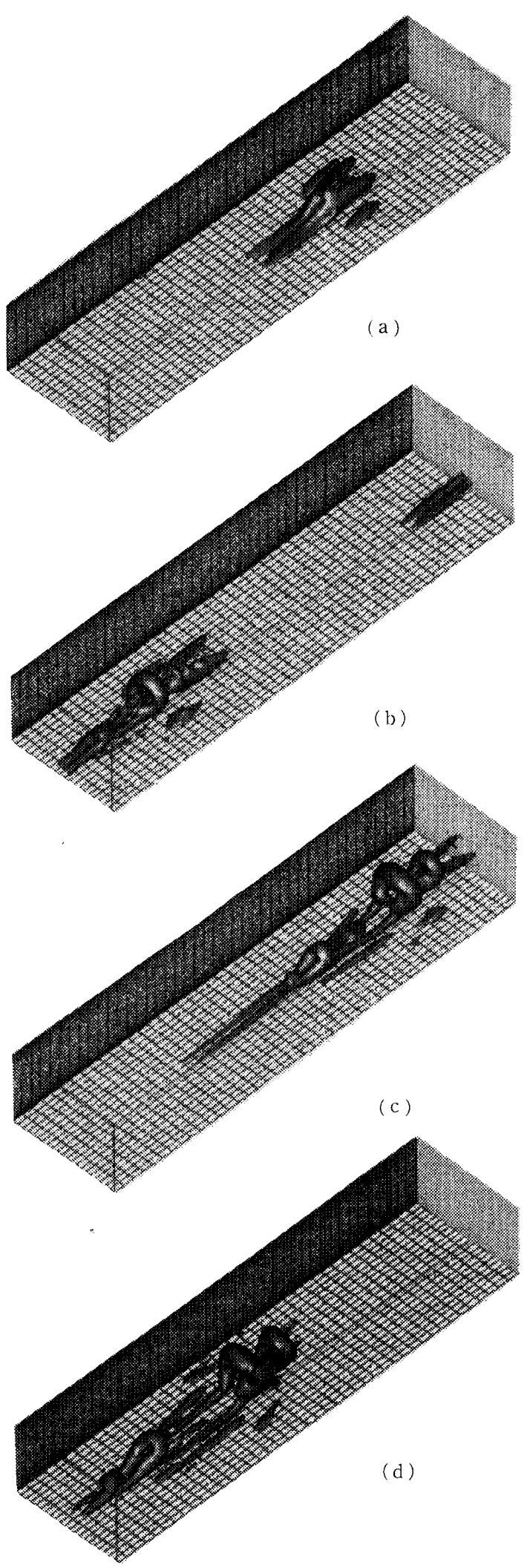

Fig. 8 Growth of a hairpin vortex in a laminer flow, (a) $T^{+}=24$, (b) $T^{+}=96$, (c) $T^{+}=168$ and (d) $T^{+}=240$
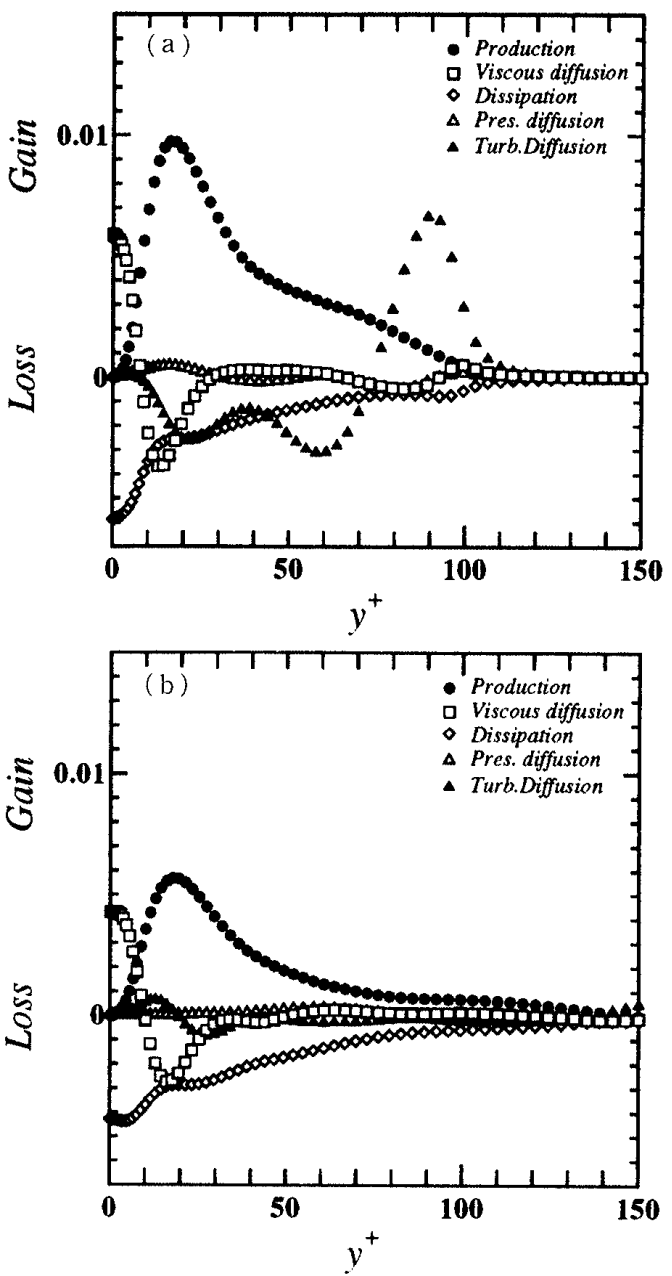

Fig. 9 Turbulent kinetic energy budget during the growth of a hairpin vortex. (a) $T^{+}=24$, (b) $T^{+}=240$

を増す。 $T^{+}=240$ ではほぼ成熟し, 最初のヘッドは溝 中心面を越えて他の半幅域に入る，実際の流れ場では このような組織構造は周开の乱机渦との干涉の結果, 消散が早まり溝中心面を越えて発達する大規模構造は ほとんどない.したがってこの時点で計算を終えた。

これらの結果はすでにZhouら ${ }^{(6)(8)}$ が報告した結果 を複製するものであるが，このような理想化した渦が 強い不規則性のある乱流場の中でどの程度に重要な役 割を果たすか検討するため，乱れエネルギの壁方向の 釣合いを調べる。図 9 は図 8 二つの時刻に対するも ので, 瞬時の空間平均を示す。図 $9(\mathrm{a})$ は $T^{+}=24$, (b)は $T^{+}=240$ の場合である。図 $9(\mathrm{a})$ はネック，へ ツドの上部構造が生成され始める時刻, 図 $9(\mathrm{~b})$ はほ

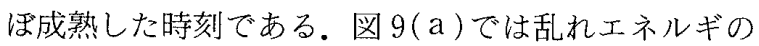
拡散項 $T_{k}$ によって下方から上部構造にエネルギが持 ち込まれ，これが上部構造の成長に消費されているこ とを示している.下方の乱れエネルギは長く伸びたレ 
ッグによって生成されるものであるからへアピン渦の 成長にはそれに先立つ長い縦渦の成長が必要であるこ とがわかる。一方, 図 8(b)の分布の著しい特徵は, 一般の十分発達した溝乱流の場合のそれとほほ相似で あることである。このことは図 $8(\mathrm{~d})$ に示したへアピ ン洞とその周辺に分布する縱渦群が不規則に変動する 場の中の基本構造であることを示している.そして， $y^{+}$が数十以下の壁近傍層にはヘッド, ネックの上部 構造がないから壁近傍層は縦渦で占められることにな る、したがって，十分発達した壁乱流の緩衝層以下の 壁近傍層では渦は縦渦としてのみ観察され，上方の構 造には影響されない。

上部構造は乱れエネルギを吸収して成長するが構造 性のない場から成長するとは考えにくく，したがって 下方の縦渦が不可久である，ただし，壁から遠い層に 縱渦が生成しうる程度に強いせん断層が存在する場合 は壁近傍の縦渦群とは無関係にそこにも同様のへアピ ン渦は成長しうると考えられる.

壁近傍乱流が自律的であるのは壁近傍の乱れの主要 な要素である縦渦がストリークの不安定により(9)(10) 形成されることが幅広く受け入れつつあるので， Jiménez ら (2) はストリークを人為的に除去する数值 実験を行ってその役割を確認している．著者らは先に 壁近傍乱流の著しい特徴の一つとして, 渦の群化を取 り上げた(11).その中で大スケール渦を除去するフィ ルタを用いて強い縦渦群のみを抽出し, その時間発展 を調べると, 渦群は急速に減衰して消隇することを示 した.このフィルタリングはストリークを除去したこ とに相当するのでストりークの役割を大規模な場で確 かめたものといえる.

しかし, 図 8 に示した成長後の渦群の上,下流およ び側面には強いストリークはない.一般にストリーク は流れ方向の速度の変動成分が $\left|\Delta u^{+}\right| \geq 3.0$ 程度の領 域をいうが，図 9 にはこの定義によるストリークはほ とんど現れない、したがって，縦渦はストリークがな い場合も成長しうる。

\section{5. 結 論}

（1）緩衝層外縁である $y^{+}=50 〜 60$ 以下の層は上 方層とのエネルギ交換を遮断すると乱れを維持しな い. しかし, それ以上の厚さになればその厚さ内で独 自に乱れを生成し維持する。このとき, 緩衝層内の乱 れの構造は普遍的で上方層のじょう乱の影響を受けな w.
（2）緩衝層が完全に層流化されても，その上方に 十分強いせん断層と十分な厚さがあれば乱れが生成さ れ壁面摩擦抗力低減率は低下する。したがって, 乱流 制御の効率を上げるには緩衝層上方の乱れの制御が必 要である.

（3）壁面上の摩擦抵抗を低減するために，壁面上 の一定の幅の層 $\left(y^{+}<35\right)$ の乱れの発生を抑制した場 合も，それに対応する自律的な乱れ構造が現れる。

（4）乱流速度分布の層流内に一対の縦渦を埋め込 み, 時間発展させると複数のへアピン渦とその周囲に 縦渦が形成される。このときレッグ部分が作る乱れエ ネルギはへアピン渦のヘッド部を成長させ，またその レッグ部周囲では複数の縦渦を再生する。壁近傍にあ る複数のレッグ部および縦渦からなる乱れエネルギの 釣合い分布は発達した溝乱流のそれにほぼ相似で, 壁 乱流の基本構造となっている.

\section{文献}

(1) 三宅裕・辻本公一・縣康明, 粗さ要素モデルによる粗面 溝乱流の DNS, 機論, 65-633, B (1999), 1613-1620.

(2) Jimenez, J. and Pinelli, A., The Autonomous cycle of Near-Wall Turbulence, J. Fluid Mech., 389(1999), 335359.

(3) 三宅裕・辻本公一, 周期的圧力こう配を有する溝乱流の 直接シミュレーション, 機論, 61-587 B(1995), 2401-2407.

(4) Goldstein, D., Handler, R. and Sirovich, L., Modeling a No-Slip Flow Boundary with an External Force Field, J. Fluid Mech, 105(1993), 354-366.

（5）鈴木雄介・三宅裕・辻本公一, 制御された壁上の組織構 造の解析, 機構論, No. 98-7(1998), A-243.

(6) Zhou, J., Adrian, R. J. and Balanchandar, S., Autogeneration of Near-Wall Vortical Structures in Channel Flow, Phys. Fluids, 8-1(1996), 288-290.

(7) Adrian, R. J. and Moin, P., Stochastic Estimation of Organized Turbulent Structure: Homogeneus Shear Flow, J. Fluid Mech., 190(1988), 531-559.

(8) Zhou, J., Adrian. R. L., Balachandar, S. and,Kendall, T. M., Mechanism for generating Coherent Packets of Hairpin Vortices in Channel Flow, J. Fluid Mech, 387 (1999), 353-396.

(9) Schoppa, W. and Hussain, F. (Panfon, R., ed), Genesis and Dynamics of Coherent Structures in Near-Wall Turbulence, Self-Sustaining Mechanisms of Wall Turbulence, (1997), 385 422, Computational Mechanics Publications.

(10) Schoppa, W. and Hussain, F., A large-Scale Control Strategy for Drag Reduction in Turbulent Boundary Layers, Phys. Fluids, 10-5(1998), 1049-1051.

(11) Tsujimoto K., Miyake, Y., Yoshikawa, T. and Morikawa, $\mathrm{T}$., Analysis of Clusterization of quasi-streamwise Vortices in Near-Wall Turbulence, JSME Int., 42 2(1999), 162-170. 